BRES 18015

\title{
Testosterone regulates substance $P$ within neurons of the medial nucleus of the amygdala, the bed nucleus of the stria terminalis and the medial preoptic area of the male golden hamster
}

\author{
Jennifer M. Swann and Sarah W. Newman \\ Department of Biological Sciences, Rutgers State Unicersity, Newark, NJ 07202 (USA) and Department of Anaromy and Cell Biology, Med. Sci. II. \\ Unic ersity of Michigan, Ann Arbor, MI 48109-0616 (USA)
}

(Accepted 31 March 1992)

Key words: Neuropeptide: Steroid; Mating behavior: Tachykinin; Immunocytochemistry; Chemosensory pathway: Limbic system

\begin{abstract}
The medial nucleus of the amygdala, bed nucleus of the stria terminalis, and medial preoptic area appear to mediate steroidal regulation of mating behavior in male rodents. The mechanism of action has not been determined. One way testosterone could enhance neuronal function is by increasing neurotransmitter levels, thus altering neuronal transmission. To assess this hypothesis, we examined the effect of castration and testosterone $t 1$ atment on substance $P$ levels in the neurons of these three brain regions. Brains from male Syrian hamsters that were (1) gonadally intact. (2) castrated for 13 weeks, or (3) castrated for 9 weeks and treated with testosterone for 4 weeks, were processed for substance $P$. and the numbers of substance $P$ immunoreactive neurons in the medial nucleus of the amygdala, bed nucleus of the stria terminalis, and medial preoptic area were determined. Castration reduced the number of substance $\mathbf{P}$ neurons in the bed nucleus of the stria terminalis and medial preoptic area relative to those in intact hamsters; the number of substance $P$ neurons in these regions was restored by testosterone treatment. Castration did not reduce the number of substance $P$ neurons in the medial nucleus of the amygdala: however, testosterone treatment increased the numbers of these neurons when compared to intacts. Thus, testosterone regulates substance $P$ levels in areas that regulate mating behavior. As substance P enhances male copulatory behavior cur results suggest tinat testesterone may regulate copulatory behavior by enhancing substance P levels in medial nucleus of the amygdala, bed nusileus of the stria terminalis and medial preoptic ureal.
\end{abstract}

\section{INTRODUCTION}

Circulating gonadal steroids are essential for the expression of normal copulatory behavior in male mammals. Removal of gonadal steroids via castration induces a gradual, permanent decrease in mating behavior that is prevented or reversed by the administration of testosterone or its metabolites 4 . While it is clear that gonadal steroids must act on neuronal systems to regulate behavior ${ }^{37}$ the underlying mechanisms by which steroids influence neuronal function are not completely understood.

Three interconnected areas of the limbic system the medial nucleus of the amygdala, the bed nucleus of the stria terminalis and the medial preoptic area have emerged as possible sites for the mediation of steroidal actions on male reproductive behavior. These areas play a role in the regulation of mating behavior in a number of species ${ }^{37}$. However, they play critical roles in the regulation of copulation in the male golden hanster. Males of this species rely almost exclusively on pheromonal cues from the female for the initiation and completion of copulation $25,43,44$. These cues stimulate chemosensory receptors in the vomeronasal organ and olfactory mucosa that project to the accessory and main olfactory bulbs, respectively ${ }^{35}$. Bilateral bulbectomy immediately and permanently eliminates copulation in male hamsters" ${ }^{31}$. Efferents from the main and accessory olfactory bulbs project directly and indirectly to the medial nucleus of the amygdala ${ }^{12.23 .38}$, which in turn projects to the medial part of the bed nucleus of the stria terminalis and the medial preoptic area ${ }^{20}$. 
Lesions of these nuclei and/or the pathways that connect them abolish or severely disrupt male hamster copulatory behavior ${ }^{23,36}$.

Three lines of evidence suggest that steroids act on these three areas to regulate copulatory behavior. First, the neurons in the medial nucleus of the amygdala, the bed nucleus of the stria terminalis and the medial preoptic area contain high concentrations of androgen and estrogen receptors ${ }^{41}$. Second, gonadal steroids regulate the activity of the neurons in these areas. Neurons in the medial nucleus of the amygdala that project to the medial preoptic area through the stria terminalis show a gradual decrease in firing rates following castration, with a time course identical to the loss of sexual behavior ${ }^{18,19}$. Finally, both testosterone and estrogen are capable of maintaining or restoring mating behavior when implanted into the medial preoptic area, the bed nucleus of the stria terminalis or the medial nucleus of the amygdala of castrated animals given systemic, subthreshold doses of these steroids ${ }^{3,24}$.

There is now an increasing body of evidence that steroids may influence mating behavior by stimulating neurotransmitter content of neurons in the amygdala and hypothalamus thereby affecting the ability of these neurons to transmit signals to their targets. Specifically, substance $P$ appears to be such a neurotransmitter or modulator ${ }^{22.29}$ and it appears to play a role in mating behavior ${ }^{14}$. Levels of this peptide are regulated by steroids in the amygdala of male rats ${ }^{13}$ and in the medial preoptic area and pituitary of female rats ${ }^{6}$, suggesting that substance $P$ may also be regulated by steroids in the medial nucleus of the amygdala, the bed nucleus of the stria terminalis and the medial preoptic area of the male hamster as well. The current study examined the response of substance $P$ to changes in steroid levels by comparing the number of substance $P$ immunolabelled perikarya in the medial nucleus of the amygdala, the bed nucleus of the stria terminalis and the medial preoptic area in hamsters that were gonadally intact, castrated or castrated and treated with testosterone.

\section{MATERIALS AND METHODS}

\section{Animals and experimental design}

Sixteen adult male Syrian hamsters Mesocricetus auratus (13-14 weeks old) were obtained from Harlan-Sprague-Dawley (Madison, WI) and divided into the following groups: intacts $(n=5)$, castrates $(n=6)$ and testosterone-treated castrates $(n=5)$. Animals in the latter two groups were deeply anesthetized with sodium pentobarbital $(0.9 \mathrm{mg} / 100 \mathrm{~g}$ b.wt. $)$ and the testes, epididymes and fat pads were bilaterally removed via a mid-scrotal incision. Testosterone-treated castrates received subcutaneous injections of testosterone $(500 \mu \mathrm{g}$ in $0.1 \mathrm{ml}$ sesame oil) every other day for 4 weeks beginning 9 weeks after castration. Hamsters were sacrificed 13 weeks after the start of the experiment.
Colchicine treatment and tissue preparation

Each hamster (anesthetized as described above) received an injection of colchicine $(320 \mu \mathrm{g} / 2 \mu \mathrm{l})$ in the right lateral ventricle 48 $h$ before perfusion. Colchicine increases the concentration of peptides within neuronal cell bodies, thus aiding in immunocytochemical visualization of peptide-containing neurons. We have found that $48 \mathrm{~h}$ is optimal for immunocytochemical labelling of cell bodies in the hamster. Results from preliminary studies indicate that survival times greater than $48 \mathrm{~h}$ decrease the number of immunohistochemically labelled neurons. Prior to perfusion, each hamster was deeply anesthetized with an overdose of sodium pentobarbital, placed on ice and perfused through the heart with $150-200 \mathrm{ml}$ of warm $\left(40^{\circ} \mathrm{C}\right)$ phosphate-buffered saline (PBS; $0.1 \mathrm{M}, \mathrm{pH} 7.4$ ) containing $0.1 \%$ sodium nitrite to promote vasodilation. This was followed by $200 \mathrm{ml}$ of ice cold fixative ( $2 \%$ paraformaldehyde and $0.25 \%$ benzoquinone (Aldrich Chemicals)), in PBS. Each brain was removed, post-fixed in a light tight container for $10-12 \mathrm{~h}$ at $4^{\circ} \mathrm{C}$ then transferred to $20 \%$ phosphate-buffered sucrose with $0.01 \%$ sodium azide before being cut into 40- $\mu \mathrm{m}$ coronal sections on a sliding microtome. Sections were stored in polyvinyl pyrolidine 47 at $-20^{\circ} \mathrm{C}$ or phosphate buffer containing $0.01 \%$ sodium azide at $4^{\circ} \mathrm{C}$ until they were immunolabelled for substance $P$.

\section{Immunocytochemical procedure}

A series of sections $120 \mu \mathrm{m}$ apart was processed from each brain. To control for variations in staining, immunocytochemical procedures were conducted on tissue from castrated, intact and/or testosterone-treated castrated animals simultaneously. Free-floating sections were soaked in $1 \%$ sodium borohydride for $30 \mathrm{~min}$, washed 3 times $(5 \mathrm{~min}$ each) in $0.1 \mathrm{M}$ phosphate buffer and incubated in monoclonal antibody directed against substance $P$ (Accurate Scientific). Antiserum to substance $P$ was diluted 1:500 in $0.1 \mathrm{M}$ phosphate buffer containing $0.3 \%$ Triton $X$ and $0.001 \%$ sodium azide. Forty-eight to $72 \mathrm{~h}$ later sections were washed in phosphate buffer, and incubated for $1 \mathrm{~h}$ at room temperature in goat anti-rat IgG (Cappel) diluted 1:50. Sections were washed in phosphate buffer and were incubated in rat peroxidase anti-peroxidase (PAP; Miles Scientific) $(1: 100)$ for $1 \mathrm{~h}$ at room temperature. The PAP complex was histochemically labelled by immersing the sections in $0.125 \%$ diaminobenzidine hydrochloride, $0.03 \%$ hydrogen peroxide and $0.015 \%$ nickel chloride in phosphate buffer for $15 \mathrm{~min}$. Sections were subsequently rinsed in water, then in phosphate buffer, mounted on gelatin-coated slides, dried, dehydrated and coverslipped with Permount.

A series of sections adjacent to those processed for immunocytochemistry was mounted and stained with Cresyl violet to aid in the identification of neuronal groups.

Immunocytochemical staining was completely blocked in a series of sections processed for immunocytochemistry following incubation of the primary antiserum with $10^{-8} \mathrm{M}$ of substance $P$ peptide (Sigma). This antiserum crossreacts somewhat with neurokinin A, a related neuropeptide found in mammalian CNS ${ }^{34}$. However as substance $P$ is found in all neurons that contain neurokinin $A^{11.46}$ this crossreactivity did not present a problem in the current study.

\section{Data analysis}

All slides were examined under brightfield illumination. Sub. stance P-immunoreactive (SPIR) neurons were identified by the presence of black-brown reaction product filling the somata and dendritic processes. To determine the location of SPIR neurons within the subdivisions of the medial nucleus of the amygdala, the bed nucleus of the stria terminalis and the medial preoptic area, immunolabelled sections were projected onto tracings of cell groupings made from adjacent sections stained with Cresyl violet. All SPIR neurons were counted throughout each of the 3 nuclei in every section of the series for every brain. In the few brains in which a section was missing, the average number of neurons contained in the available seciions was added to the total. Initial inspection of the data revealed heterogeneity of variance among experimental groups. Therefore, differences between the number of SPIR neurons within the medial preoptic area, the bed nucleus of the stria terminalis and 
the medial nucleus of the amygdala were determined using a one way analysis of variance of the square root of the total number of substance $\mathbf{P}$ neurons in each brain region. Post hoc significance was determined with Fisher's protected least significant differences test ${ }^{16}$.

\section{RESULTS}

\section{Bed nucleus of the stria terminalis}

Substance $\mathbf{P}$ neurons were distributed throughout the postcommissural part of the bed nucleus of the stria terminalis in gonadally intact male hamsters (Figs.
$1 \mathrm{~B}-\mathrm{F}, 2)$. The majority of these neurons $(95 \%)$ were located in the posteromedial (BNSTpm) subdivision of this nucleus with only an occasional SPIR neuron occurring in the posterointermediate (BNSTpi) subdivision as well. These subdivisions correspond to those described in the rat ${ }^{30}$. The average number of substance $P$ neurons in intact hamsters was $540.4 \pm 66.1$ $(\overline{\mathrm{x}} \pm$ S.E.M.) (Figs. 1B-F, 2A, 3). These neurons contained a dark black to brown reaction product and appeared to have $2-5$ processes. The actual number of
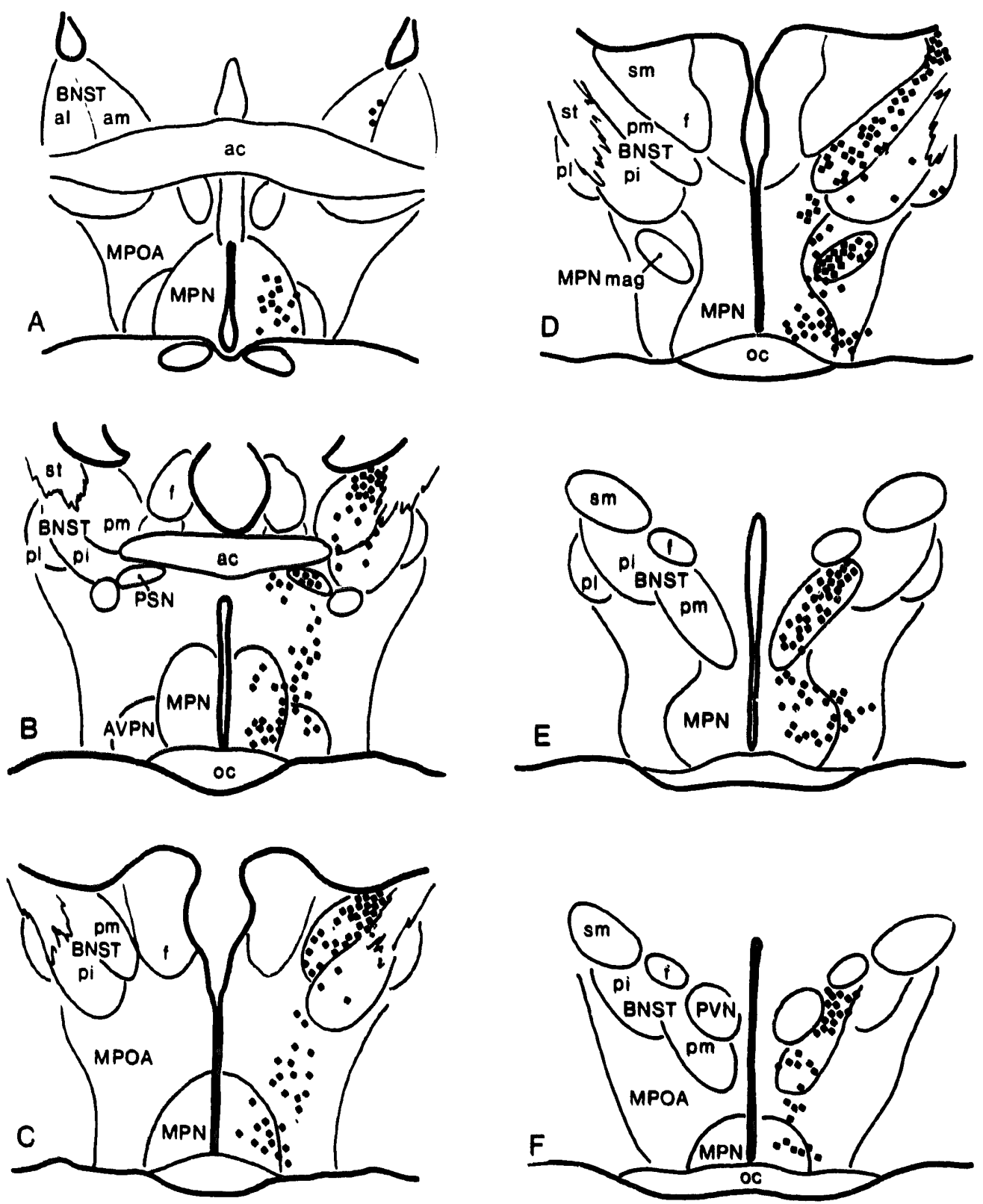

Fig. 1. Distribution of substance P-immunoreactive neurons throughout the bed nucleus of the stria terminalis and the medial preoptic area in the male Syrian hamster. Each symbo! in the bed nucleus of the stria terminalis represents 3 neurons; each symbol in the medial preoptic area represents 4 neurons. Abbreviations: AVPN, anteroventral preoptic nucleus; ac, anterior commisure; BNST, bed nucleus of the stria terminalis; , a a medial preoptic nucleus; MPN, medial preoptic nucleus: MPOA. medial preoptic area; oc, optic chiasm: PSN, parastrial nucleus; PVN, paraventricular nucleus; $\mathrm{sm}$, stria medullaris; st, stria terminalis. BNST subdivisions are those of Moga et al. ${ }^{30}$; MPOA subdivisions are those of 

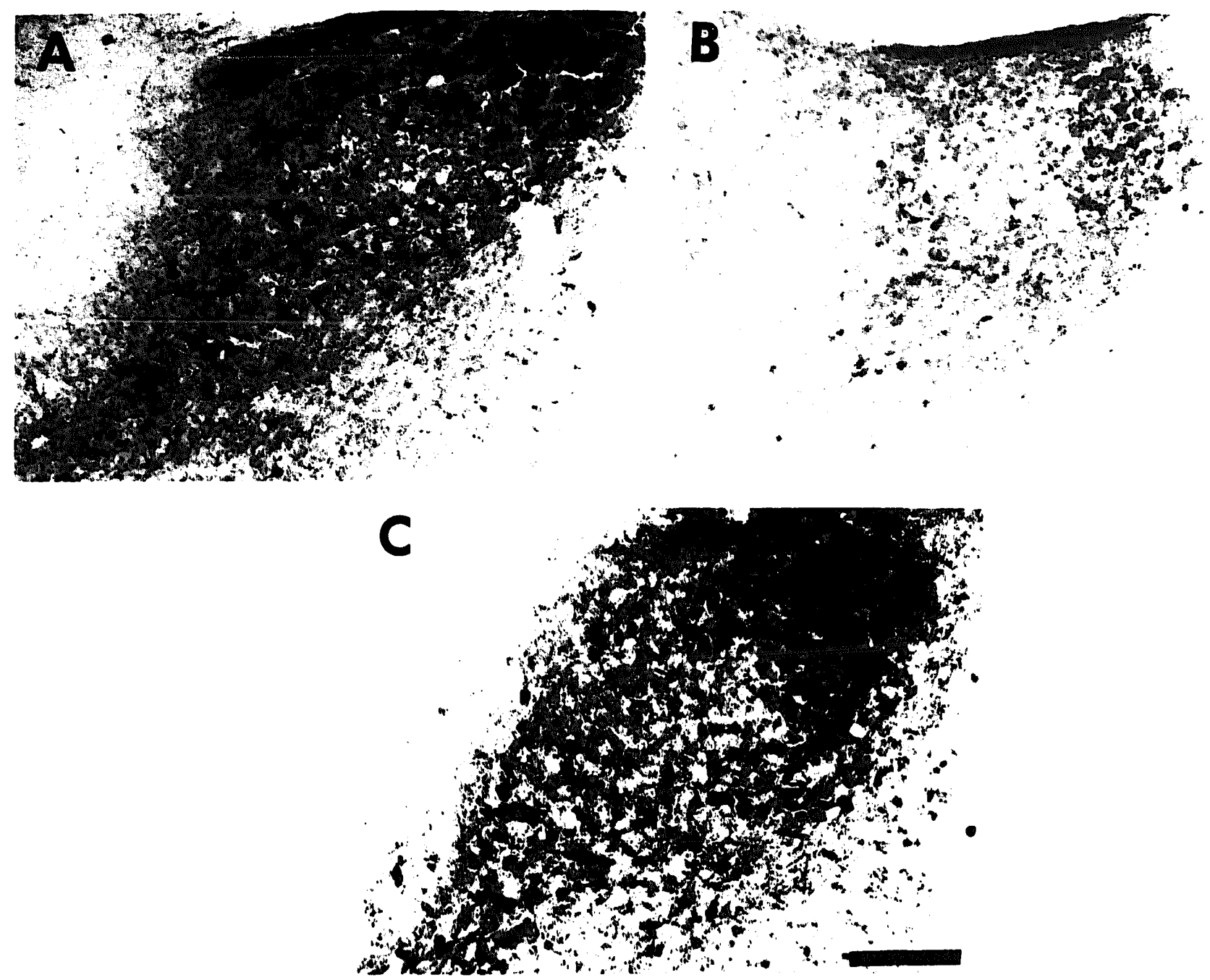

Fig. 2. Substance $P$ immunoreactivity in coronal sections through the postcommissural part of the bed nucleus of the stria terminalis at the level indicated in Figure IC. A: gonadal intact, B: castrated, $C$ : castrate treated with testosterone. Note the abundance of substance $P$ cells and heavy fiber labelling in $A$ and $C$ and the absence of cell bodies and the light fiber labelling in the castrated animal (B).

processes per cell was difficult to discern due to the heavy concentration of immunoreactive fibers in this area.

Castration reduced the total number of immunoreactive cells in the bed nucleus of the stria terminalis to $13-50 \%$ of the number observed in intact animals (Fig. 3). The BNSTpm of castrated animals contained an average of $153.3 \pm 38.8$ neurons, significantly fewer than the average of intact animals $(P<0.001)$. This decrease in the number of SPIR cells occurred throughout the BNSTpm but was particularly striking in the dorsal part of the nucleus, just below the lateral ventricle, where substance $P$ staining is the heaviest in intact animals (Figure 1B-D, 2A, B). Castration also appeared to reduce the intensity of staining as well. DAB reaction product appeared light brown or gray in the majority of the neurons in the BNSTpm of cas-

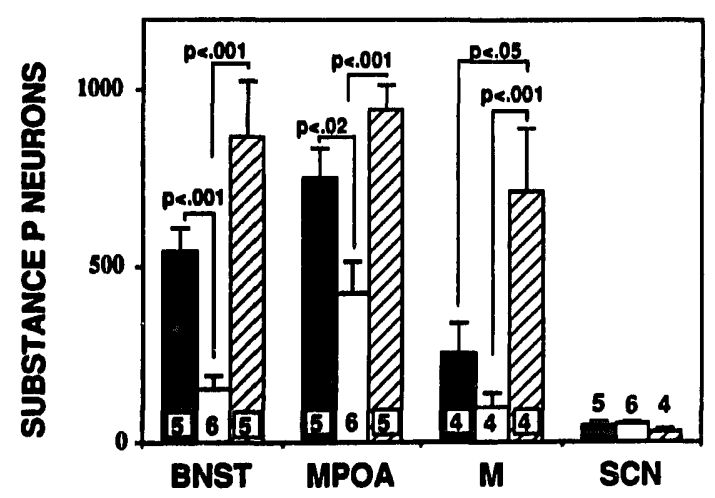

Fig. 3. Mean number of substance P-containing cells in the medial nucleus of the amygdala (M), the posteromedial part of the bed nucleus of the stria terminalis (BNST) and the medial preoptic area (MPOA) and the suprachiasmatic nucleus (SCN) of intact ( $\square$ ), castrate ( $\square$ ) and castrated hamsters treated with testosterone ( $\square$ ). Probability of significance is give above each statistically different pair. The number within each bar indicates the number of animals in each group. 
trated hamsters, in sharp contrast to the dark, black reaction product observed in the SPIR neurons of the intact males.

Testosterone treatment reversed the effect of castration on the BNSTpm (Fig. 2C). Castrates treated with testosterone had an average of $867.6 \pm 158.1$ neurons in the BNSTpm, significantly greater than that in castrates $(P<0.001$, Fig. 3). Further, 4 of the 5 castrates treated with testosterone had more SPIR neurons in the BNSTpm than were found in intact controls, but on average this difference was not statistically significant. The majority of the labelled neurons in these animals contained dark, black immunoreaction product comparable in intensity to that found in intact hamsters, suggesting that the amount of immunoreactivity per neuron was also restored with testosterone treatment. The testosterone-treated hamsters also contained a large number of SPIR cells in the posterointermediate part of the bed nucleus of the stria terminalis.

\section{The medial preoptic area}

Intact hamsters had an average of $749.6 \pm 83.6$ SPIR neurons in the medial preoptic area (MPOA; Fig. 3). These cells were not confined to any nuclear subdivision of the MPOA, but instead were distributed in a band of cells that extended from the ventral part of the rostral medial preoptic area in the lateral part of the medial preoptic nucleus (MPN) beneath the body of the anterior commissure (Fig. 1A), dorsolaterally to an area ventral to the posterointermediate part of the BNST (Fig. 1B-D). Few SPIR neurons were found in the MPOA rostral to the body of the anterior commissure. SPIR neurons in the MPOA could be assigned to 1 of 2 groups by location, morphology and intensity of immunoreactivity. One group consisted of large, multipolar, darkly staining neurons located (1) just lateral to the MPN and just ventral to the posterointermediate BNST and (2) in an oval-shaped cluster just lateral to the MPN in the MPN magnocellular, as defined by Maragos and coworkers ${ }^{27}$ (Figs. 1D, 4A). The second
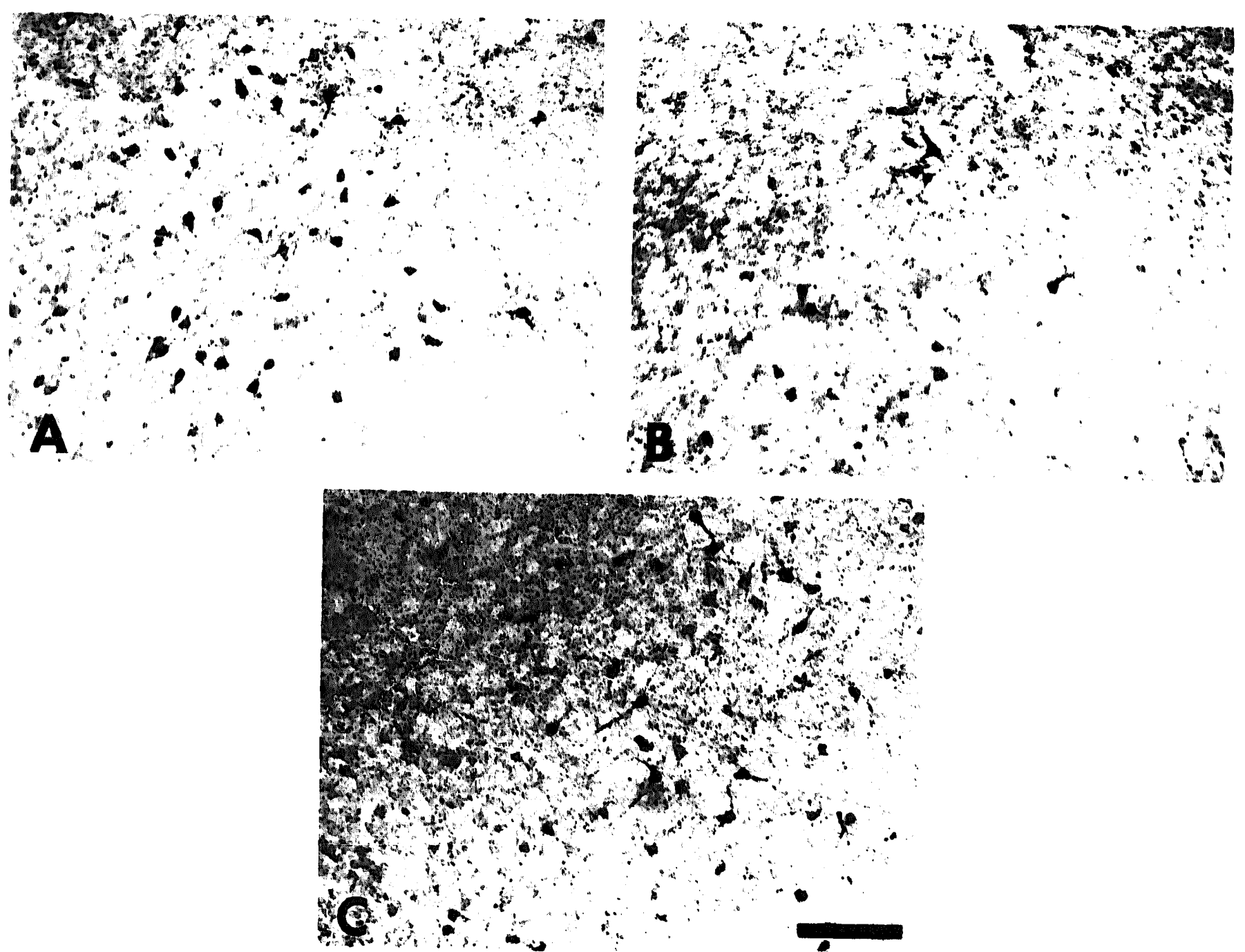

Fig. 4. Substance $P$ immunoreactivity in coronal sections through the magnocellular part of the medial preoptic nucleus at the level indicated in Figure ID. A: intact animal, B: castrated, C: castrate treated with testosterone. Note the decrease in the number of labelled cells in B compared to those in $A$ and $C$. 
group, most of which were in the MPN, were smaller in size and lightly stained. Throughout the MPOA these smaller neurons were located ventromedial to the large darkly stained, SPIR neurons.

Castration significantly reduced the number of SPIR neurons in the medial preoptic area $i P<0.02$; Fig. 4B). Castrates had an average of $420.5 \pm 91.6$ labelled neurons in the MPOA (Fig. 3). This reduction was uniform throughout the MPOA, without regard to location or cell type. The cell types showed a similar distribution as that seen in intact animals, i.e., the larger multipolar cells in the dorsolateral group stained darkly and the ventromedial group of smaller cells stained lightly.

Again, testosterone treatment reversed the effect of castration. The mean number of SPIR neurons in the MPOA of testosterone-treated castrates was $942 \pm 70.7$, significantly greater than the number of SPIR neurons in untreated castrates $(P<0.001)$ (Figs. 3, 4C), but not significantly greater than that observed in intact hamsters.

\section{The medial nucleus of the amygdala}

SPIR neurons were found throughout the medial nucleus of the amygdala. Fig. 5 illustrates the distribution of these cells in the midrostral to caudal levels of this nucleus. The highest density of these neurons occurred in the posterodorsal subdivision of the nucleus ${ }^{15}$ (Fig. 5C-E). In this region, substance $P$ neurons and fibers formed a dense plexus. Neurons in these areas were small to medium in size with 2-3 processes. As in the BNST, the density of the fiber labelling prevented accurate determination of the number of processes per cell. The majority of SPIR cells in the intact animals contained dark, black reaction product, which filled the perikarya, dendrites and axons (Fig. 6A). The rostral part of the medial nucleus of the amygdala (not shown in Fig. 5) did not consistently contain a high concentration of SPIR neurons; in some animals, many labelled neurons were distributed throughout the medial anci anterior cortical nucleus of the amygdala, while in other animals only a few cells were found in the more rostral parts of these nuclei. SPIR cells were consistently observed in the caudal third of the medial nucleus. Therefore, quantitative analysis was restricted to this region which contained an average of $251 \pm 86.7$ SPIR neurons in intact males.

The average number of SPIR neurons in this nucleus in castrates was $102 \pm 37.2$, which did not differ from that in intact hamsters (Fig. 3). However, the immunoprecipitate in these neurons appeared light gray to brown in contrast to the dark brown to black of the SPIR neurons in the medial nucleus of intact
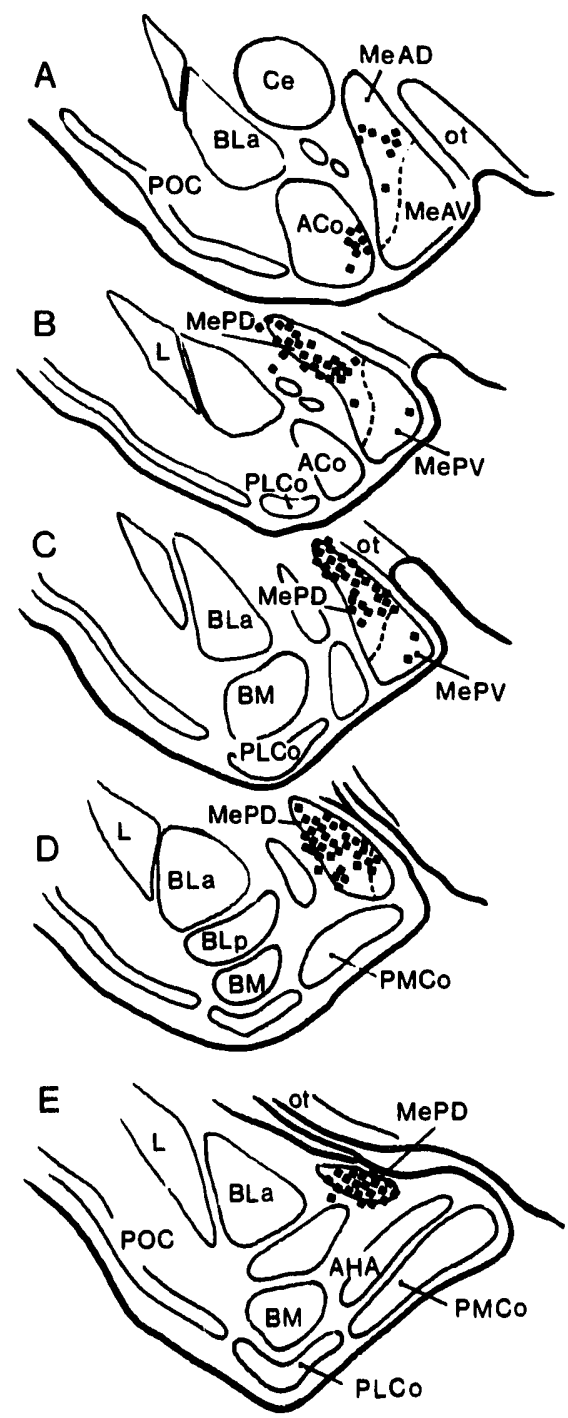

Fig. 5. Distribution of substance $P$ immunoreactive neurons in the posterior part of the medial nucleus of the amygdala of the male Syrian hamster. Each symbol represents 5 neurons. Abbreviations: ACo, anterior cortical nucleus; BLa, basolateral nucleus, anterior: BLp, basolateral nucleus, posterior; BM. basomedial nucleus; Ce, central nucleus; L, lateral nucleus; MeAD, medial nucleus, anterodorsal; MeAV, medial nucleus, anteroventral; MePD. medial nucleus, posterodorsal; MePV, medial nucleus, posteroventral; POC. primary olfactory cortex; PLCo, posterolateral cortical nucleus; PMCo, posteromedial cortical nucleus; ot, optic tract. Subdivisions of the medial nucleus are described in Gomez et al. ${ }^{15}$.

hamsters, suggesting that the quantity of antigen was less in these cells than in those of intact animals (Fig. 6B).

Testosterone-treated castrates had a greater number of SPIR neurons in the posterodorsal medial nucleus $(710 \pm 181.7)$ than castrates $(P<0.001)$ or intact hamsters $(P<0.05$; Fig. 3$)$. These neurons and their processes contained dark, black reaction product (Fig. 6C).

\section{Suprachiasmatic nucleus}

SPIR cells were located in the lateral edge of the caudal third of the suprachiasmatic nucleus in ham- 

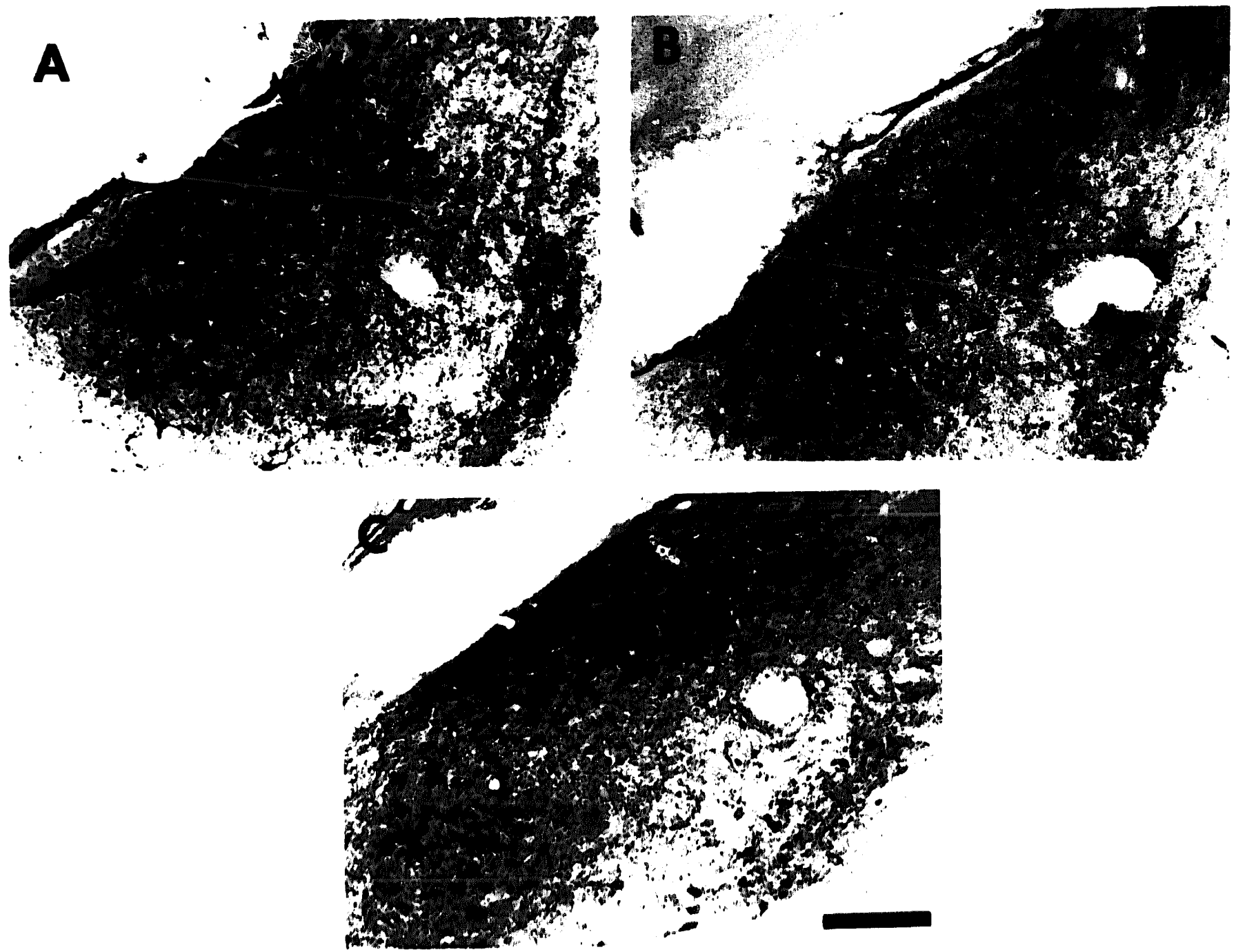

Fig b. Substance of immunoreactivity in coronal sections through the posterodorsal part of the medial nucleus of the amygdala ut about the level shown in Figure 5D. A: intact animal, B: cistrated, C: cistrate treated with testessterone. Note the abundance of substance P cells and heavy fiber labelling in the intuct and testosterone-treated castrute and the absence of cell bodies and the light fiber labelling in the castrated animal.
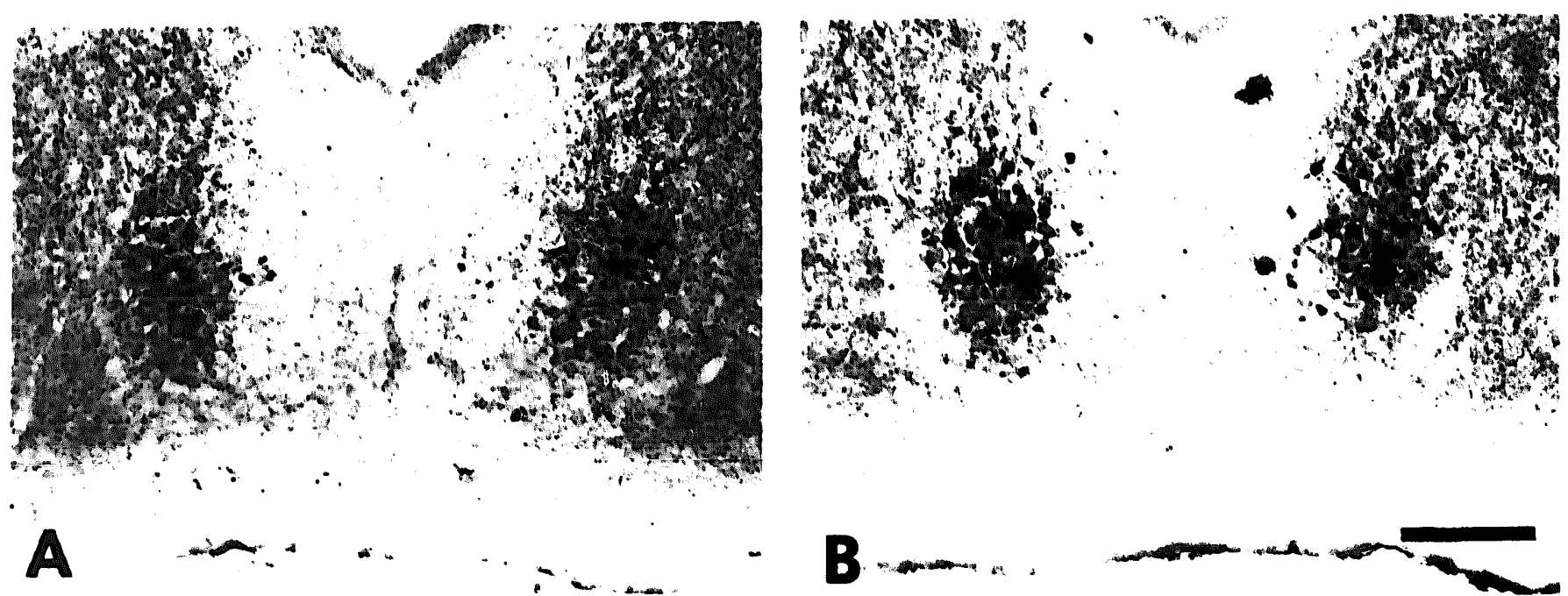

Fig. 7. Substance $P$ immunoreactivity in coronal sections through the suprachiasmatic nucleus of an intact (A) and castrate (B) hamster. Note the similarity in the number of neurons labelled in the two photographs. 
sters in each of the groups (Fig. 7). Castration had no effect on the number of immunoreactive cells in this area. The average number of immunoreactive neurons were: intact, $49 \pm 9.37$; castrated, $50 \pm 9.11$; testosterone-treated castrates, $28.8 \pm 11.55$. (Fig. 3 ).

\section{DISCUSSION}

The results of the present study suggest that castration induces a significant decrease in the number of SPIR neurons in the medial part of the bed nucleus of the stria terminalis and the medial preoptic area in the male golden hamster. Long term castrates treated with testosterone contained the same number of SPIR neurons as gonadally intact males suggesting that the decrease in immunoreactivity following castration is restored by testosterone treatment. The manipulation of gonadal steroids had different effects on SPIR in the medial nucleus of the amygdala. In this area, castration alone did not significantly affect the number of SPIR neurons, yet, treatment with testosterone increased their number significantly indicating that testosterone regulates SPIR in the medial nucleus of the amygdala as well. Our results are supported by those of Kream et al. ${ }^{21}$, who found that testosterone regulates substance P content of the hypothalamus of the Syrian hamster. The results of the present study extend these findings by localizing the change in substance $P$ content to cell bodies within the bed nucleus of the stria terminalis and the medial preoptic area. Testosterone may also regulate substance $P$ content in the fibers in these areas. Reduction in SPIR fiber content of the medial nucleus of the amygdala ${ }^{1.3}$ and bed nucleus of the stria terminalis ${ }^{20}$ has been observed in castrated rats. Whether or not testosterone also regulated the substance $P$ content of fibers in the bed nucleus of the stria terminalis, the medial preoptic area and the medial nucleus of the amygdala of the hamster could not be assessed in the present study due to the use of colchicine. These studies should be pursued. Substance P-containing neurons in the medial nucleus of the amygdala and the bed nucleus of the stria terminalis have been shown to project to the medial preoptic area in the hamster ${ }^{3.3}$ and the rat ${ }^{42}$. As substance $P$ appears to serve as a neuromodulator in these areas a decrease in fiber content would indicare a decrease in substance $P$ at the presynaptic terminal and may indicate more precisely the effect of steroids on synaptic transmission in these areas.

These results contrast with those of previous reports that failed to find changes in substance $P$ content in male rats in these areas following castration or testosterone treatment ${ }^{0,42}$. The discrepancy may be due to differences in the length of time the animals were without testosterone prior to sacrifice. Both studies in rats examined SPIR 2 or 3 weeks after castration compared to 13 weeks in the present study. In our preliminary studies in hamsters significant decreases in substance $P$ levels were not apparent until 8-12 weeks after castration, suggesting that significant differences in SPIR might have been observed in rat tissue if the animals had survived for longer intervals after castration and/or steroid treatment. An alternative interpretation is that testosterone exerts different effects on substance $\mathbf{P}$ levels in these two rodent species. However, this explanation seems less likely, based on observations that castration and testosterone treatment alter substance $P$ fiber content in the medial nucleus of the amygdala ${ }^{13}$ and bed nucleus of the stria terminalis ${ }^{25}$ in male rats.

Other gonadal steroids may play a role in the regulation of substance $P$ immunoreactivity. Testosterone is metabolized into estrogen and dihydrotestosterone (DHT) within the medial nucleus of the amygdala, the bed nucleus of the stria terminalis and the medial preoptic area ${ }^{x .28}$ in the hamster suggesting that the effect of testosterone on SPIR may be mediated by these estrogenic and androgenic metabolites. The role of estrogen in the regulation of substance $P$ in these areas has not been examined in male rodents. There is evidence that estrogen plays a role in substance $P$ production in female rats. Treatment with estradiol increases the levels of mRNA for the substance $P$ precursor in the hypothalamus of female rats". and the number of SPIR neurons s.5 $^{4 .}$ and levels of SPIR ${ }^{17.32}$ in the hypothalamus of female rats is highest on the day of estrus, when estrogen levels are high. Moreover. treatment with estrogen has been shown to lower the substance $P$ content in the pituitary of both male and female prepubertal rats"'. The role of non-aromatizable androgens in the regulation of substance $P$ levels in the CNS has not been examined. Treatment with DHT increases substance $P$ content in the pituitary of both male and female prepubertal rats, suggesting that non-aromatizable androgens may also stimulate substance P production "'. The results of the present investigation in conjunction with these earlier studies indicate future experiments are necessary to evaluate the role of androgens and estrogens in the regulation of neuronal levels of substance $P$ in the medial nucleus of the amygdala, the bed nucleus of the stria terminalis and the medial preoptic area.

Although the role of substance $P$ in hamsters is unknown evidence obtained from studies on rats indicates that it may play a neurotransmitter role in these nuclei. High concentrations of substance $P^{5.7}$ anu ; ub- 
stance $P$ receptors ${ }^{\text {tII }}$ have been identified in each of these areas. Substance $P$ has been shown to stimulate the firing rates of neurons in both the medial preoptic area $i^{24}$ and amygdala 22 . In addition, substance $P$ has beren shown to facilitate mating behavior when injected into the MPOA of male rats ${ }^{14}$. The medial nucleus of the amygdala, the bed nucleus of the stria terminalis and the medial preoptic area each play critical roles in the regulation of mating behavior in the Syrian hamster $^{23.36}$. Thus, the present results support the hypothesis that steroidal regulation of substance $P$ is a mechanism underlying steroidal regulation of mating behavior.

In the hamster, unlike the rat, the bed nucleus of the stria terminalis and the medial nucleus of the amygdala play critical but different roles in the regulation of male mating behavior ${ }^{23.36}$. Anogenital investigation of the female is an important component of male rodent sexual behavior. This behavior is especially important in hamsters. In this species, pheromones secreted by the female can induce copulatory behavior from a male when placed on the body of an anesthetized test male ${ }^{43,44}$. Lesions of the medial nucleus of the amygdala eliminate copulation and decrease anogenital investigation ${ }^{2.3}$. The medial nucleus of the amygdala, in turn, projects to both the bed nucleus of the stria terminalis and medial preoptic area. Bilateral lesions of the medial preoptic area disrupt copulation without affecting precopulatory investigation in malc hamsters. Appropriately placed lesions of the bed nucleus of the stria terminalis decrease anogenital investigatory behavior without affecting copulation. These areas are densely innervated by substance $P$ fibers and studies in the rat indicate that they contain substance $P$ receptors ${ }^{41}$ although this has not been investigated in the hamster. Thus, the hypothesis that substance $P$ facilitates mating through actions on these sites awaits further experimental assessment in the hamster.

In contrast to its effects on gonadally intact rats, substance $P$ fails to restore mating behavior when injected into the medial preoptic area of castrated rats ${ }^{14}$. However, these results do not rule out the possibility that substance $P$ mediates steroid-induced changes in mating behavior. Testosterone influences a wide variety of neuropeptides, neurotransmitters and receptors that may work together to regulate mating behavior. For example, substance $P$ is colocalized with neurokinin $A^{11}$ and dynorphin ${ }^{34}$ within the neurons of the medial nucleus of the amygdala, the bed nucleus of the stria terminalis and the medial preoptic area in the hamster. Both substance $\mathrm{P}^{14}$ and dyzorphin ${ }^{2}$ have been shown to influence mating behavior in the intact rat. Castration decreases the levels of all 3 peptides (Swann, unpublished results). Restoration of mating behavior in castrates could, therefore, require simultaneous administration of substance $P$, neurokinin $A$ and dynorphin. Thus, substance $P$ may play an important role in steroidal regulation of mating behavior that cannot be properly assessed without further information on the anatomical and functional relationships among substance $\mathbf{P}$ and other neuroactive substances. In addition, castration could reduce the concentration of substance $P$ receptors and therefore the responsiveness of the tissue to injected peptide.

The mechanism by which steroids influence substance $P$ levels in the neurons of the limbic system has not been completely determined. Both estrogen receptor and cyclic AMP binding regions are located within the promoter region of the gene that encodes substance $P^{9}$. Neurons in the medial nucleus of the amygdala, the bed nucleus of the stria terminalis and the medial preoptic area contain androgen and estrogen receptors ${ }^{41}$. Some of the estrogen concentrating cells also contain substance $P$, suggesting that gonadal steroids may directly influence the peptide production in some of these neurons'. Alternatively, steroids could manipulate the synthesis and or release of other neurotransmitters or neuromodulators that could regulate substance $P$ levels via post-synaptic second messenger systems.

In summary, our results suggest that substance $P$ may mediate the effect of gonadal steroids on mating behavior via actions on the medial nucleus of the amygdala, the bed nucleus of the stria terminalis and the medial preoptic area. The precise role of substance $P$ in the regulation of the function of these nuclei and copulatory behavior in the Syrian hamster awaits further study.

Acknowledgments. This research was supported by NIH NS20629 atwarded to S.W.N., the morphology core of Reproductive Sciences it the University of Michigan Department of Anatomy, the Biomedical Research Support Grant PHS RR (07059-22 awarded to Rutgers University, NSF RII 88-17677 awarded to J.M.S. and the Rutgers University Research Council. The authors would like to thank Nick Macchione. Patria Adames and Kerri Powell for assistance in the preparation of the tissue, data acquisition and preparation of the figures and Drs. Keith Anderson. Charles Neal, Brad Powers and Saralh Kollak for their critical evaluation of the manuscript.

\section{REFERENCES}

I Akesson, T.R and Micevych, P.E., Tachykinin immunoreactive neurons accumulate estrogen in sexually dimorphic nuclei of the rat limbic system, Neurosci. Abstr.. 16 (1990) 325.

2 Band, L.C. and Hall, E.M., Morphine and dynorphin (1-13) microinjected into the medial preoptic area and nucleus accumbens: effects on sexual behavior in male rats, Brain Res., 524 (1990) $77-84$.

3 Baum, M.J., Tobet, S.A., Starr, M.S. and Bradshaw, W.G., Implantation of dihydrotestosterone propionate into the lateral sep- 
tum or medial amygdala facilitates copulation in castrated male rats given estradiol systemically, Horm. Behac., 16 (1982) 208-22.3.

4 Beach, F.A., Historical origins of modern research on hormones and behavior, Horm. Behav., 15 (1981) 325-376.

5 Ben-Ari, U., La Salle, G.L. and Kanazawa, I., Regional distribution of substance $P$ within the amygdaloid complex and bed nucleus of the stria terminalis, Neurosci. Lett., 4 (1977) 299-302.

6 Brown, E.R., Harlan, R.E. and Krause, J.E., Gonadal steroid regulation of substance $P(S P)$ and $5 P$-encoding messenger ribonucleic acids in the rat anterior pituitary and hypothalamus, Endocrinology, 126 (1990) 330-340.

7 Brownstein, M.J., Mroz, E.A., Kizer, J.S., Palkovits, M. and Leeman, S.E., Regional distribution of substance $P$ in the brain of the rat, Brain Res., 116 (1976) 299-305.

8 Callard, G.V., Hoffman, R.A., Petro, Z. and Ryan, K.J., In vitro aromatization and other androgen transformations in the brain of the hamster (Mesocricetus aurutus), Biol. Reprod., 21 (1979) 33-38.

9 Carter, M.S. and Krause, J.E., Structure, expression, and some regulatory mechanisms of the rat preprotachykinin gene encoding substance $P$, neurokinin $A$, neuropeptide $K$ and neuropeptide $G$, J. Neurosci., 10 (1990) 2203-2214.

10 Coslovsky, R., Braverman, L.E., Leeman, S.E. and Aronin, N., The differential effects of thyroid and gonadal hormones on substance $\mathbf{P}$ content in the anterior pituitary of the prepubertal rat, Endocrinology, 117 (1985) 2198-2202.

11 Damlama, M. and Swann, J.M., Colocalization of substance K and substance $P$ in the mating behavior pathway of the male golden hamster, Neurosci. Abstr., 15 (1989) 562.

12 Davis, B.J., Macrides, F., Youngs, W.M., Schneider, S.P. and Rosene, D.L., Efferents and centrifugal afferents of the main and accessory olfactory bulbs in the hamster, Brain Res. Bull., 3 (1978) 59-72.

13 Dees, W.L. and Kozlowski, G.P., Effects of castration and ethanol on amygdaloid substance $P$ immunoreactivity, Neuroendocrinology, 39 (1984) 231-235.

14 Dornan. W.A. and Malsbury, C.W., Peptidergic control of male rat sexual behavior: the effects of intracerebral injecrions of substance P and cholecystokinin. Physiol. Beha1'., 46 (1989) 547556.

15 Gomez, D.M. and Newman, S.W., Medial nucleus of the anygdala in the Syrian hamster: a quantitative Golgi analysis of gonadal hormone regulation of neuronal morphology, Anar. Rec., $231(1901) 498-509$.

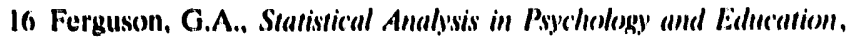
McGraw-Hill, New York, 1976, pp. 24(1)-261.

17 Frankfurt, M., Siegel, R.A., Sim, I., and Wuttke, W., Estrous cycle variations in cholecystokinin and substance $P$ concentrations in discrete areas of rat brain, Neurocendocrinology, 42 (1986) 226-231.

18 Kendrick, K.M. and Drewitt, R.F., Testosterone reduces refractory period of stria terminalis neurones in rat brain, Science, 204 (1979) 877-879.

19 Kendrick, K.M., The effect of castration on stria terminalis neurone absolute refractory periods using different antidromic stimulation loci, Brain Res., 248 (1982) 174-176.

20 Kevetter, G.A. and Winans, S.S., Connections of the corticomedial amygdala in the golden hamster. I. Efferents of the 'vomeronasal amygdala', J. Comp. Neurol., 197 (1981) 81-98.

21 Kream, R.M., Clancy, A.N., Kumar, M.S.A., Schoenfeld, T.A., and Macrides, F., Substance $P$ and luteinizing hormone releasing hormone levels in the brain of the male golden hamster are both altered by castration and testosterone replacement. Neuroendocrinology, 46 (1987) 297-305.

22 Le Gal La Salle, G. and Ben-Ari, Y., Microiontophoretic effects of substance $P$ on neurons of the medial amygdala and putamen of the rat, Brain Res., 135 (1977) 174-179.

23 Lehman M1.N. aisJ Winans, S.S. Vomeronasal and olfactory pathways to the amygdala controlling male hamster sexual behavior: autoradiographic and behavioral analyses, Brain Res., 240 (1982) 27-41.

24 Lisk, R.D. and Greenwald, D.P., Central plus peripheral stimulation by androgen is necessary for complete restoration of copula- tory behavior in the male hamster, Neuroendocrinology', 36 (1983) 211-217.

25 Macrides, F., Johnson, P.A. and Schneider, S.P., Responses of the male golden hamster to vaginal secretion and dimethyl disulfide: attraction versus sexual behavior, Behal: Biol., 20 (1977) 377-386.

26 Malsbury, C.W. and Brown, S.A., Testosterone masculinizes the development of the substance $P$ innervation of the medial nucleus of the amygdala and the bed nucleus of the stria terminalis, Neurosci. Ahstr., 15 (1989) 562.

27 Maragos, W.F., Newman, S.W., Lehman, M.N. and Powers, J.B., Neurons of origin and fiber trajectory of amygdalofugal projections to the medial preoptic area in Syrian hamsters, J. Comp. Neurol., 280 (1989) 59-71.

28 Martini, L., The $5 \alpha$-reduction of testosterone in the neuroendocrine structures. Biochemical and physiological implications, Endocr. Rev., 3 (1982) 1-25.

29 Mayer, M.L. and MacLeod, N.K., The excitatory action of substance $P$ and stimulation of the stria terminalis bed nucleus on preoptic neurons, Brain Res., 166 (1979) 206-210.

30 Moga M.M., Saper, C.B. and Gray, T.S., Bed nucleus of the stria terminalis: cytoarchitecture, immunohistochemistry and projection to the parabrachial nucleus in the rat. J. Comp. Neturol., 283 (1989) 315-332.

31 Murphy, M.R. and Schneider, G.E., Olfactory bulb removal eliminates mating behavior in the male golden hamster, Science, 167 (1970) 302-303.

32 Mycevych, P.E., Matt, D.W. and Go, V.L.W., Concentrations of cholecystokinin, substance $P$ and bombesin in discrete regions of male and female rat brain: sex differences and estrogen effects, Exp. Neurol., 100 (1988) 410-425.

33 Neal Jr., C.R. and Newman, S.W., Prodynorphin- and substance P-containing neurons project to the medial preoptic area in the male Syrian hamster, Brain Res., 546 (1991) 119-131.

34 Neal Jr., C.R. Swann, J.M. and Newman, S.W., The colocalization of substance $P$ and prodynorphin immunoreactivity in neurons of the medial preoptic area, bed nucleus of the stria terminalis and the medial nucleus of the amygdala of the Syrian hamster, Brain Res., 496 (1989) 1-1.3.

35 O'Connell, R.J. and Meredith, M.. Effects of volutile and nonvolatile chemical signals on male sex behaviors mediated by the main and accessory olfactory systems. Behas: Neurosci., 98 (1984) $108.3-109.3$.

36 Powers, J.B., Newman, S.W. and Bergondy, M.L., MPOA and BNST lesions in male Syrian hamsters: differential effects on copulatory and chemoinvestigatory behaviors, Behar: Brain Res.. 2.3 (1987) $181-195$.

37 Sachs, B.D. and Meisel, R.L., The physiology of malc sexual behavior. In E. Knobil and J. Neill (Eds.). The Physiology of Reproduction, Raven, New York, 1988, pp. 14(1)3-1412.

38 Scalia, F. and Winans, S.S. The differential projections of the olfactory bulbs in mammals, $J$. Comp. Neurol., 161 (1975) 31-56.

39 Shults, C.W., Johnson, P. and Gage, F.H., Comparison of substance K-like and substance P-like fibers in the rat hippocampus, Brain Res., 426 (1987) 290)-296.

40 Shults, C.W., Quirion, R., Chronwall, B., Chase, T.N. and O'Donahue, T.L., A comparison of the anatomical distribution of substance $P$ and substance $P$ receptors in the rat central nervous system, Pcptides, 5 (1984) 1097-1128.

4l Simerly, R.B., Chang, C., Muramatsu, M. and Swanson. L.W., Distribution of androgen and estrogen receptor mRNA-containing cells in the rat brain: an in situ hybridization study. J. Comm). Neurol., 294 (1990) 76-95.

42 Simerly, R.B., Young, B.J., Capozza, M.A. and Swanson, L.W., Estrogen differentially regulates neuropeptide gene expression in a sexually dimorphic olfactory pathway, Proc. Natl. Acad. Sci.. U.S.A., 86 (1989) 4760-4770.

4.3 Singer, A.G., Agosta, W.C., O'Connel, R.J.. Pfaffmann, C., Bowen, D.V. and Field, F.V., Dimethyl disulfide: an attractant pheromone in hamster vaginal secretion, Science. 191 (1976) 948-950.

44 Singer, A.G., Macrides, F., Clancy, A.N. and Agosta, W.C., 
Purification and analysis of a proteinaceous aphrodisiac pheromone from hamster vaginal discharge, J. Biol Chem.. 261 (1986) $13323-13326$.

45 Tsuro. Y.. Hisano, S.. Okamura, Y.. Tsukamoto, N. and Daikoku. S., Hypothalamic substance $P$ containing neurons. Sex dependent topographical differences and ul:rastructural transformations associated with stages of the estrus cycle, Brain Res., 305 (1984) $331-341$.
46 Warden, M.K. and Young, W.S., Distribution of cells containing $m$ mNAs encoding substance $P$ and neurokinin $B$ in the rat central nervous system, J. Comp. Neurol., 272 (1988) 90-113.

47 Watson Jr., R.E., Wiegand, S.J., Clough, R.W. and Hoffman, G.E.. Use of a cryoprotectant to maintain long term peptide immunoreactivity and tissue morphology, Peptides, 7 (1986) 155159. 